\title{
Humoral immune response to Mycobactrium tuberculosis cell wall fraction and lipoarabinomannan antigens in Bangladeshi patients with active tuberculosis
}

\author{
Md. Mohiuddin and J. Ashraful Haq
}

Department of Microbiology, Ibrahim Medical College, 122 Kazi Nazrul Islam Avenue, Dhaka, Bangladesh

\begin{abstract}
Background and objective: This study focused on the analysis and comparison of humoral immune response to Mycobacterium tuberculosis (MTB) cell wall fraction (CWF) and lipoarabinomannan (LAM) antigens.

Methods: Sera from adult patients with active pulmonary tuberculosis and age and sex matched healthy individuals were tested for immunoglobulin (Ig) $\mathrm{M}$ and IgG antibodies to CWF and LAM by enzyme linked immunosorbent assay (ELISA).

Results: The mean OD values of serum IgM and IgG antibodies against CWF of TB patients was not significantly $(\mathrm{p}=0.52, \mathrm{p}=0.45)$ different from that of healthy control population. However, the mean OD values of serum $\operatorname{IgM}$ and $\operatorname{IgG}$ against LAM were significantly $(\mathrm{p}=0.049, \mathrm{p}=0.001)$ higher in TB cases than that of healthy individuals.

Conclusion: The present study has revealed that $\mathrm{IgM}$ and $\mathrm{IgG}$ antibody to LAM may be used in serodiagnosis of $\mathrm{TB}$ while response to $\mathrm{CWF}$ in active $\mathrm{TB}$ case is restricted in our population.
\end{abstract}

IMC J Med Sci 2016; 10(2): 58-60

\section{Introduction}

Tuberculosis (TB) caused by Mycobacterium tuberculosis (MTB) is one of the leading causes of death in the world. The estimated incidence of TB and its annual mortality in Bangladesh is 225 and 45 per 100,000 populations [1]. Early diagnosis and treatment of TB patients is crucial for the control of $\mathrm{TB}$ [2]. In the recent years, understanding of humoral immune response to MTB and the detection of MTB antigen specific antibodies has been an important tool in the diagnosis of TB cases [3]. This is particularly important for pediatric and extra pulmonary tuberculosis and in those unable to produce sputum. Thus, exploring the antibody response to defined MTB antigens might be of great benefit for early diagnosis and control of $\mathrm{TB}$ as well as to understand the immunity to tuberculous infection.

The proteins of MTB induce a variable degree of humoral immune responses in infected people. The most studied proteins of MTB are ESAT-6 (early secretory antigen target), culture filtrate protein (CFP), 38kDa, $16 \mathrm{kDa}$ and Ag85 complex. Other MTB components eliciting humoral immune response are cell wall fraction (CWF) and lipoarabinomannan (LAM). The ability of these proteins to elicit serological response makes them to be utilized as the candidates for serodiagnosis of TB. Antigen85 complex, CFP and LAM of $M$. tuberculosis elicits detectable IgG response in tuberculosis patients. Sensitivity and specificity of assays utilizing antibodies to LAM ranged from $80.3-93 \%$ and $91-100 \%$ respectively [4-7]. 
Many investigators assayed humoral immune response to mycobacterial antigens and evaluated different antigens as candidate for serodiagnostic test to detect active tubercular infection. The success is so far variable. But till today, there is no reported study on humoral immune response to CWF and LAM antigens in Bangladeshi population either with active tuberculosis or in healthy people. Therefore, the present study was undertaken to determine the antibody response to CWF and LAM antigens of MTB.

\section{Materials and methods}

The study was conducted in the Department of Microbiology, Bangladesh Institute of Research and Rehabilitation in Diabetes, Endocrine and Metabolic Disorders (BIRDEM), Dhaka. Informed consent was obtained from each of the participant.

Study population: Adult patients with active pulmonary tuberculosis were enrolled in the study. Active TB was confirmed by clinical features, positive acid fast bacilli (AFB) in sputum smear and culture. Age and sex matched healthy individuals were enrolled in the study as healthy control. All the healthy individuals were BCG vaccinated and they did not have past history of TB or contact with known TB case. About $5 \mathrm{ml}$ of blood was collected from each participant with aseptic precautions by venipuncture. The serum was immediately separated and stored at $-20^{\circ} \mathrm{C}$ until used.

Antigens: Purified CWF and LAM antigens of MTB were used. The antigens were obtained from the Department of Microbiology, Immunology and Pathology, Colorado State University, 1682 Campus Delivery, Fort Collins, CO 80523, USA.

Detection of antibody by ELISA: IgM and IgG antibodies to CWF and LAM antigens were determined by enzyme linked immunosorbent assay (ELISA). ELISA was performed as described by Voller et al [8]. Briefly, the 96 well EIA plate was coated with respective antigen (CWF or LAM) at a concentration of $5 \mu \mathrm{g} / \mathrm{ml}$. The optimum working concentration of each antigen was predetermined by checkerboard method using antigen concentration of $2.5 \mu \mathrm{g} / \mathrm{ml}, 5 \mu \mathrm{g} / \mathrm{ml}$ and $10 \mu \mathrm{g} / \mathrm{ml}$.
Initially, checkerboard method was also used to optimize the working serum dilution (1:400 for IgM and 1:1600 for IgG). IgM or IgG anti-humanHRP conjugate was used at a dilution of 1:5000 (MP Biomedicals, USA). Absorbance optical density (OD) was read at 450nm in Human ELISA reader.

Interpretation of the result: The concentration of antibody was expressed in OD at a particular dilution of both patient and healthy control samples. Significance of difference of mean OD value of IgM and IgG antibodies against respective antigens was calculated by independent student's t test.

\section{Results}

Antibody response to CWF and LAM was determined in sera of 30 confirmed cases of tuberculosis and 30 healthy subjects. Table-1 shows the antibody response to CWF and LAM antigens. The mean OD values of serum IgM and IgG antibodies against CWF of TB patients was not significantly $(p=0.52, p=0.45)$ different from that of healthy control population. The mean OD values of serum IgM and IgG against LAM were significantly $(p=0.049, p=0.001)$ higher in $\mathrm{TB}$ cases than that of healthy individuals.

Table-1: Antibody response to CWF and LAM in tuberculosis and healthy participants

\begin{tabular}{lcccc}
\hline \multirow{2}{*}{$\begin{array}{l}\text { Study } \\
\text { population }\end{array}$} & \multicolumn{4}{c}{ Antibody to (Mean OD $\pm S E$ ) } \\
\cline { 2 - 5 } & \multicolumn{3}{c}{ CWF } & \multicolumn{2}{c}{ LAM } \\
\cline { 2 - 5 } & IgM & IgG & IgM & IgG \\
\hline $\begin{array}{l}\text { TB patients } \\
n=30\end{array}$ & $0.61 \pm 0.06$ & $1.50 \pm 0.12$ & $0.92 \pm 0.11$ & $1.84 \pm 0.07$ \\
$\begin{array}{l}\text { Healthy } \\
n=30\end{array}$ & $1.19 \pm 0.88$ & $1.38 \pm 0.10$ & $1.13 \pm 0.05$ & $1.15 \pm 0.05$ \\
$p$ value & $\mathrm{P}=0.52$ & 0.45 & 0.065 & $\mathrm{p}=0.0001$ \\
\hline
\end{tabular}

\section{Discussion}

Analysis of humoral immune response to different antigens of MTB is important to understand their role in immunity or susceptibility to mycobacterial infection. In view of this, attempt has been made to determine the humoral immune response to $\mathrm{CWF}$ and LAM antigens of MTB.

It was found that the IgM and IgG antibody response to CWF were not significantly different in 
TB patients and healthy individuals. It is hypothesized that the individuals become probably susceptible to develop active tuberculosis or infection if they are unable to mount initial antibody response against this antigenic component of MTB. In other words, if anybody exposed to Mycobacterium may not develop active diseases if the individual is capable of mounting antibody response to CWF. Alternatively, CWF may not play any role in conferring immunity to MTB infection.

In our study, the mean concentration of $\operatorname{IgM}$ antibody to LAM was similar in both TB patients and healthy individuals. The presence of such background IgM antibody to LAM in the healthy individuals might be due high endemicity of tuberculosis in the community and subclinical exposure to MTB earlier in life as Bangladesh is a high TB burden country. However, we observed significantly higher $\mathrm{IgG}$ response against LAM in active tuberculosis cases. Similar higher IgG antibody response to LAM has been found in patients with TB and is being used as a marker for serodiagnosis of TB [4-7, 9]. Significant IgG response to arabinomannan has been found following $\mathrm{BCG}$ vaccination indicating its role in defense against mycobacterial infection [10].

The present study, therefore, revealed that IgM and IgG antibody to LAM may be used in serodiagnosis of $\mathrm{TB}$ while response to $\mathrm{CWF}$ in active TB case is restricted in our population. Lack of antibody response to some antigens may indicate underlying pathophysiology of MTB infection.

\section{References}

1. World Health Organization. Global tuberculosis report 2016. Geneva: World health organization 2016; 214 p.

2. Steingart KR, Flores LL, Dendukuri N, Schiller I, Laal S, Ramsay A, et al. Commercial serological tests for the diagnosis of active pulmonary and extrapulmonary tuberculosis: an updated systematic review and meta-analysis. PLoS Med 2011; 8(8): e1001062. doi: 10.1371/ journal.pmed.1001062.
3. Wu X, Yang Y, Zhang J, Li B, Lian Y, Zhang C, Dong M. Comparison of antibody responses to seventeen antigens from Mycobacterium tuberculosis. Clin Chim Acta 2010; 411(1920): 1520-1528. doi: 10.1016/j.cca.2010.06. 014.

4. Boehme C, Molokova, E, Minja, F, Geis S, Loscher T, Maboko L, Koulchin V, Hoelscher M. Detection of mycobacterial lipoarabinomannan with an antigen capture ELISA in unprocessed urine of Tanzanian patients with suspected tuberculosis. Trans Royal Soc Trop Med Hyg 2005; 99(12): 893-900.

5. Brown RM, Cruz O, Brennan M, Gennar ML, Schlesinger L, Sheiky YAW, Hoft DF. Lipoarabinomannan reactive human secretory immunoglobulin, a responses induced by mucosal Bacille Calmette-Guerin vaccination. J Infect Dis 2003; 187: 513-17.

6. Chan ED, Reves R, Belisle JT, Brennan P J, Hahn WE. Diagnosis of tuberculosis by a visually detectable immunoassay for lipoarabinomannan. Am J Respir Crit Care Med 2000; 161(5): 1713-19.

7. Sada E, Aguilar D, Torres M, Herrera T. Detection of lipoarabinomannan as a diagnostic test for tuberculosis. J Clin Microbiol 1992; 30(9): 2415-2418.

8. Voller A, Bartlett A, Bidwell DE. Enzyme immunoassays with special reference to ELISA techniques. J Clin Path 1978; 31: 507-520.

9. Demkow U, Balas CB, Filewska M Sobiecka M, Kus J, Szturmowicz M, Zielonka T, Augustynowicz-Kopec E. Humoral immune response against mycobacterial antigens in bronchoalveolar fluid from tuberculosis patients. J Physiol Phamacol 2005; 56(Suppl 4): 79-84.

10. Chen T, Blanc C, Eder AZ, Prados-Rosales $\mathrm{R}$, Souza ACO, Kim, RS, et al. association of human antibodies to arabinomannan with enhanced mycobacterial opsonophagocytosis and intracellular growth reduction. The $J$ Infec Dis. 2016; 214(2):300-310. doi:10.1093/ infdis/ jiw141. 